\title{
Proteolytic Activities of Oral Bacteria on ProMMP-9 and the Effect of Synthetic Proteinase Inhibitors
}

\author{
Guang Jie Bao ${ }^{1}$, Kirsti Kari², Taina Tervahartiala ${ }^{2}$, Timo Sorsa ${ }^{2}$ and Jukka H. Meurman ${ }^{2, *}$ \\ ${ }^{1}$ Stomatology School of North-West University for Nationalities, China and ${ }^{2}$ Institute of Dentistry, University of Hel- \\ sinki, and Department of Oral and Maxillofacial Diseases, Helsinki University Central Hospital, Helsinki, Finland
}

\begin{abstract}
Tissue reactions to bacteria lead to proinflammatory reactions involving matrix metalloproteinases (MMPs). Synthetic protease inhibitors may offer new possibilities to regulate bacterial proteases. We investigated proteolytic activities of certain periodontal bacteria, their effects on the latent proMMP-9, and the effects of synthetic MMP inhibitors and a serine protease inhibitor Pefabloc. The strains studied were Porphyromonas gingivalis, Prevotella intermedia, Peptostreptoccus micros, Prevotella nigrescens, Fusobacterium nucleatum, and 5 Aggregatibacter actinomycetemcomitans serotypes. Their gelatinolytic activities and the effects of certain synthetic MMP inhibitors and Pefabloc were analyzed by zymography. Bacterial effects on proMMP-9 conversion were investigated by Western immunoblot. All investigated periodontal bacteria produced gelatinolytic cell-bound and extracellular proteinases which could fragment latent proMMP-9, suggesting co-operative processing cascades in oral tissue remodeling. A. actinomycetemcomitans produced the weakest gelatinolytic activity. Synthetic proteinase inhibitors exhibited slight but clear reductive effects on the bacterial proteolytic activities. We conclude that targeted anti-proteolytic treatment modalities against bacterial-host proteolytic cascades can be developed.
\end{abstract}

Key Words: Oral micro-organisms, pro-matrix metalloproteinase-9, activation, proteolytic activity, synthetic proteinase inhibitors.

\section{INTRODUCTION}

Tissue reaction to bacteria leads to an excessive host inflammatory response. Inflammatory cells secrete matrixdegrading proteinases, including matrix metalloproteinases (MMPs). MMPs can degrade and modify almost all matrix and basement membrane proteins in growth and in normal tissue turnover [1-2]. Elevated MMP levels, especially neutrophil gelatinase B (MMP-9) together with lesser extent neutrophil collagenase-2 (MMP-8) are considered as potential markers for tissue destruction in inflammation [1-5]. The severity and course of tissue destruction in oral infections can be monitored by assessing oral fluid MMP-8 levels [6, 7]. MMP-9 and - 8 have also been shown to exert anti-inflammatory or defensive characteristics [8].

In inflammation, gelatinase B (MMP-9) is often accompanied by MMP-8 and granulocyte elastase $[1-9,10]$. There is evidence that MMP-9 also increases during chronic inflammation [11]. Plasma MMP-9 seems to provide a useful marker of inflammation as it correlates with the leukocyte count and is not associated with the lipid profile [12]. Söder et al. [13] have shown that periodontal microorganisms can induce host response with increased release of MMP-9 and MMP-8 in the periodontal pockets. Simultaneously, higher MMP-9 concentrations were detected in blood samples of the patients indicating that this enzyme might either seep into the circulation from inflammatory cells in the periodon-

*Address correspondence to this author at the Institute of Dentistry, PB 41, FI-00014 University of Helsinki, Finland; Tel. +358-9-19127272; Fax +358-9-19127517; E-mail: jukka.meurman@helsinki.fi tal pockets and/or that periodontal bacteria can trigger its upregulation also in blood. The MMPs are synthesized as inactive proenzymes (proMMPs) and most are usually activated extracellularly to be catalytically competent. The enzyme activity is controlled by endogenous and specific tissue inhibitors (TIMPs) [14].

Periodontal bacteria, such as Porphyromonas gingivalis, Prevotella intermedia, Peptostreptococcus micros, Prevotella nigrescens, Fusobacterium nucleatum, and Aggregatibacter actinomycetemcomitans, have been identified in sub-gingival plaque as putative pathogens [15]. These and other respective species can be useful in clinical decision making especially when diagnosing and treating patients with periodontal infections [16]. Our knowledge is still sparse regarding the actual pathogenic mechanisms and interactions between bacteria and host tissue in oral infections. We set this study out to investigate the proteolytic effect of certain bacteria with special emphasis on proMMP-9 and the effects of synthetic proteinase inhibitors.

\section{MATERIAL AND METHODS}

\section{Bacterial Strains, Cultivation and Sample Preparation}

Six putative periodontal pathogenic bacterial species were involved in this study. The used strains were $P$. gingivalis ATCC 33277, P. intermedia ATCC 25611, $P$. micros ATCC 33270, P. nigrescens ATCC 33563, F. nucleatum ATCC 25586 and 5 serotypes (a, b, c, d, e) of A. actinomycetemcomitans ATCC 29523 (a), ATCC 43718 (b), ATCC 33384 (c), ATCC 787 (d), ATCC 37399 (e). 
The strains were grown in Brain Heart Infusion broth (BHI) (Difco Laboratories, Detroit, MI, USA) supplemented with hemin $(1 \mathrm{mg} / \mathrm{l})$ and menadione $(0.5 \mathrm{mg} / \mathrm{l})$ at $37^{\circ} \mathrm{C}$ to their early stationary phase, which was determined by measuring the growth curves spectrophotometrically. A. actinomycetemcomitans serotypes were cultivated in $5 \%$ $\mathrm{CO}_{2}$ atmosphere for $8 \mathrm{~h}$ and the other strains anaerobically $\left(80 \% \mathrm{~N}_{2}, 10 \% \mathrm{H}_{2}\right.$ and $\left.10 \% \mathrm{CO}_{2}\right)$ for $48 \mathrm{~h}$. Purity of each strain was monitored by Gram stain. Both cell fractions and supernatant fractions were used in this study.

The cells were harvested by centrifugation at 14,000 rpm for $20 \mathrm{~min}$ at $4^{\circ} \mathrm{C}$, washed 3 times with neutral phosphate buffer saline (PBS) and rediluted in PBS so that the final concentrations of the cells were twice higher of the original concentration for $P$. gingivalis and 4 times higher for the other species. The cell samples were sonicated on ice until cells were disrupted. The disruption of the cells was detected by phase-contrast microscope.

After centrifugation the supernatant fractions of the growth media were collected and lyophilized to get ten-fold higher concentrations. The activity of $P$. gingivalis was high enough without concentration.

\section{Assay of Gelatinolytic Proteinase Activity of the Bacteria}

For the measurements of gelatinolytic activity the samples of either supernatant or bacteria cells containing $5 \mu \mathrm{l}$ of $P$. gingivalis, $8 \mu \mathrm{l}$ of $P$. intermedia, $15 \mu \mathrm{l}$ of $P$. micros, $P$. nigrescens, $F$. nucleatum or different serotypes of $A$. actinomycetemcomitans were incubated in dark with $5 \mu \mathrm{l}$ of Laemmli's sample buffer without reductant for $2 \mathrm{~h}$ at RT for zymography. Low range prestained SDS-PAGE standards (Bio-Rad, Hercules, CA, USA) served as molecular weight markers. Zymography with $8 \%$ sodium dodecyl sulfatepolyacrylamide gel electrophoresis (SDS-PAGE) containing $1 \mathrm{mg} / \mathrm{ml}$ gelatin fluorescent labelled with 2-methoxy-2, 4diphenyl-3-2H furanone (MDPF, Fluka, Buchs SG, Switzerland) as substrate was used. After electrophoresis, the gels were washed with Tris- $\mathrm{HCl}$ buffer, $\mathrm{pH} 7.5$, containing $25 \%$ Tween $80,0.02 \% \mathrm{NaN}_{3}$, and then for $30 \mathrm{~min}$ with the same buffer supplemented with $0.5 \mathrm{mM} \mathrm{CaCl} 2$ and $1 \mu \mathrm{M} \mathrm{ZnCl}$. Finally the gels were incubated in $50 \mathrm{mM}$ Tris- $\mathrm{HCl}$ buffer $\mathrm{pH} 7.5$, containing $0.02 \% \mathrm{NaN}_{3}, 0.5 \mathrm{mM} \mathrm{CaCl}_{2}$ and $1 \mu \mathrm{M}$ $\mathrm{ZnCl}_{2}$ for overnight up to 7 days to detect gelatinolytic activity of proteinases. During incubation in the last buffer, different $\mathrm{pH}$ of $7.5,6.5,5.5,4.5$ and 4.0 were used to detect the optimum working condition of the bacterial gelatinolytic proteinases. The gels were monitored under UV-light within 1 to 7 days, stained with Coomassie Brilliant Blue, scanned using GS-700 Imaging Densitometer and analyzed by Quantity One -program (Bio-Rad).

\section{The Effects of Oral Bacteria on proMMP-9}

The molecular forms of MMP-9 were detected by modified [17] Western blotting kit according to protocol recommended by the manufacturer (GE Healthcare, Amersham, UK). Aliquots of $2.5 \mu \mathrm{l}(20 \mathrm{ng} / \mu \mathrm{l})$ of human recombinant proMMP-9 (Invitek GmbH, Berlin, Germany) were incubated with culture media samples of $P$. gingivalis, $P$. intermedia, $P$. micros, $P$. nigrescens, $F$. nucleatum, and different serotype of $A$. actinomycetemcomitans strains at $37^{\circ} \mathrm{C}$ for different periods of time ( $2 \mathrm{~h}, 4 \mathrm{~h}, 6 \mathrm{~h}, 8 \mathrm{~h}$ and $24 \mathrm{~h})$. The samples of cell fractions were prosessed accordingly. The same sample volumes as in zymography assay were used. Because of the strong enzyme activity of $P$. gingivalis, shorter time of incubations (0 $\mathrm{min}, 20 \mathrm{~min}, 40 \mathrm{~min}$ and 60 $\mathrm{min})$ were also studied. For the positive control proMMP-9 was co-incubated with aminophenylmercuric acetate (APMA, Sigma, St. Louis, MO, USA) for $2 \mathrm{~h}$ at $37^{\circ} \mathrm{C}$. ProMMP-9 without APMA was used as negative control. The incubated samples were boiled for $5 \mathrm{~min}$ with the same Laemmli's sample buffer as in zymography assay. The gels were blotted onto nitrocellulose membrane according to instructions of the manufacturer. The primary antibody used was polyclonal anti-human MMP-9 (Calbiochem, Darmstadt, Germany) and the secondary antibody anti-rabbit IgG horseradish peroxidase (1:800 dilution) (GE Healthcare). The proteins were visualized using ECL system and scanned by GS-700 Imaging Densitometer for data analysis as described above for zymograms.

\section{Effect of Synthetic MMP Inhibitors and Pefabloc on the Bacterial Proteinases}

To determine the inhibitory effects of different synthetic MMP inhibitors on periodontal bacteria, $0.2 \mathrm{mM}$ Ilomastat (ILM, Chemicon International, Inc., Temecula, CA, USA), EDTA (Merck KGaA, Darmstadt, Germany), CMT3, CMT308 (Collagenex Inc., Newtown, PA, USA), CTT1 (18) and Pefabloc (PFB, a serine protease inhibitor, Boehringer Mannheim GmbH, Mannheim, Germany) were tested in this study. The CMTs have lost their antimicrobial activity but retained their ability to inhibit mammalian MMPs [17]. Each synthetic inhibitor were dissolved in $\mathrm{dH}_{2} \mathrm{O}$ and diluted with TNC-buffer to final concentration of $0.2 \mathrm{mM}$. The inhibitors were incubated together with the bacterial supernatants and cell bound fractions for $2 \mathrm{~h}$ at $37^{\circ} \mathrm{C}$ in dark. The same sample volumes as in zymography assay were used.

The gelatinolytic activity was measured as previously described with zymography method using MDPF-gelatin as substrate $[18,19]$. The zymograms were analyzed by BioRad Model GS-700 Imaging Densitometer using the Molecular Analyst Program with correction of background values and results are expressed as arbitary units [18]. The respective samples without inhibitors were used as controls.

\section{Statistical Analyses}

The inhibition test was repeated 3 times and the inhibition results were compared to the control data using Student's $t$ test with SPSS for Windows, version 13.0. P values less than 0.05 were considered statistically significant.

\section{RESULTS}

\section{Proteolytic Activity of the Bacteria}

All the putative periodontal pathogens studied showed proteolytic activity identified and measured by gelatin zymography. $P$. gingivalis yielded molecular weight bands at the area of $70-100 \mathrm{kDa}$ and beyond $200 \mathrm{kDa}$. P. intermedia, $P$. micros, and $P$. nigrescens gave strong bands around 130$170 \mathrm{kDa}$. In addition, $P$. intermedia yielded a band at 60 $\mathrm{kDa}$. The results were similar for both the cell supernatant or cell bound fractions. Fig. (1) represents proteolytic activity of cell supernatants. The cell bound fractions of F. nuclea- 


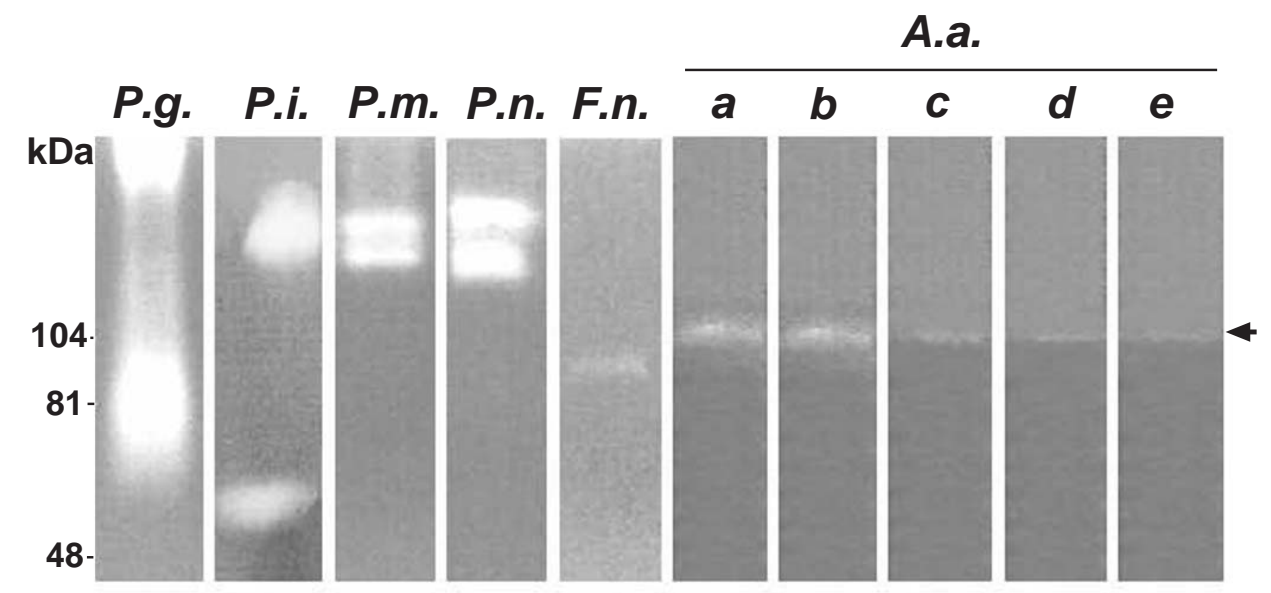

Fig. (1). Gelatinolytic activities in cell supernatants of the growth media of P. gingivalis (P.g.), P. intermedia (P.i.), P. micros (P.m.), P. nigrescens (P.n.), F. nucleatum (F.n.) and A. actinomycetemcomitans (A.a.) were studied with zymographic method. The gelatinolytic activities at 103-107 kDa produced by five serotypes of $A . a(\mathrm{a}, \mathrm{b}, \mathrm{c}, \mathrm{d}, \mathrm{e})$ are indicated by arrow.

tum and serotypes a and d of A. actinomycetemcomitans did not show any gelatinolytic activity whereas serotypes b, c, and e gave the same bands as the supernatant samples (data not shown).

The $\mathrm{pH}$ differences in incubation buffer did not have any effect on the proteinase activities of $P$. gingivalis, $P$. intermedia, $P$. micros, $P$. nigrescens and A. actinomycetemcomitans in $\mathrm{pH}$ range 7.5-5.5. However, when the $\mathrm{pH}$ dropped to 4.5-4.0, the bands of $P$. intermedia, $P$. micros and P. nigrescens were markedly fainted (data not shown).

\section{The Effects of Oral Bacteria on proMMP-9}

Western immunoblot analysis showed that supernatant of $P$. gingivalis, $P$. intermedia, $P$. micros, $P$. nigrescens, $F$. nucleatum (Fig. 2), and A. actinomycetemcomitans (data not shown) growth media fragmented the $92 \mathrm{kDa}$ proMMP-9 to the 60 and 77-82 kDa lower molecular species of MMP-9. The activity of $P$. gingivalis growth media was so strong that it was possible to detect even after shorter incubation times (data not shown). After 6h incubation proMMP-9 was found to be completely degraded to undetectable small peptides (Fig. 2).

\section{Effects of the Synthetic MMP Inhibitors and a Synthetic Serine Proteinase Inhibitor Pefabloc on Bacterial Pro- teinases}

The effects of $P$. gingivalis, $P$. intermedia, $P$. micros, $P$. nigrescens pre-incubations with ILM, EDTA, CMT3, CMT308, CTT1 and PFB on gelatin zymography are shown in Fig. (3A and B). Among all the inhibitors tested, ILM inhibited $P$. micros cell bound proteases, EDTA affected $P$. gingivalis and $P$. intermedia cell bound proteases as well as the $P$. nigrescens supernatant proteases, CMT3 inhibited $P$. intermedia cell bound proteases, CMT308 inhibited P. gingivalis cell bound proteases, CTT1 inhibited P. micros supernatant proteases and $P$. intermedia and $P$. micros cell bound proteases. Their gelatinolytic activities were reduced when compared with the respective original sample activities. These differences were statistically significant (P

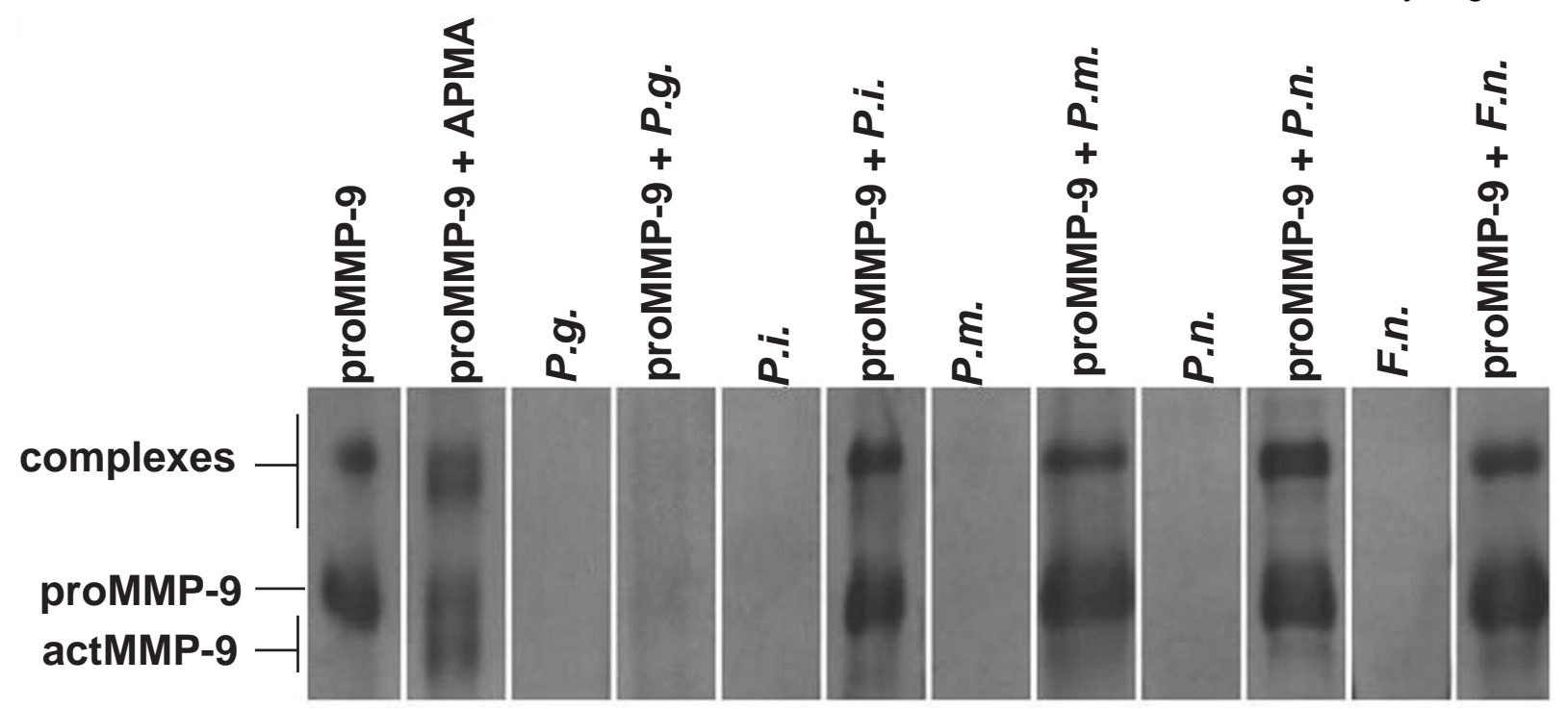

Fig. (2). Activation of proMMP-9 by supernatants of the growth media of P. gingivalis (P.g.), P. intermedia (P.i.), P. micros (P.m.), P. nigrescens (P.n.), F. nucleatum (F.n.) (Fig. 2) were studied by ECL Western blot. ProMMP-9 was incubated with the supernatants at $37^{\circ} \mathrm{C}^{\circ}$ for $6 \mathrm{~h}$. All the strains were able to convert the $92 \mathrm{kDa}$ proMMP-9 to the 60 and $77-82 \mathrm{kDa}$ lower molecular size forms of MMP-9. 


\section{A. Inhibition of cell fractions}

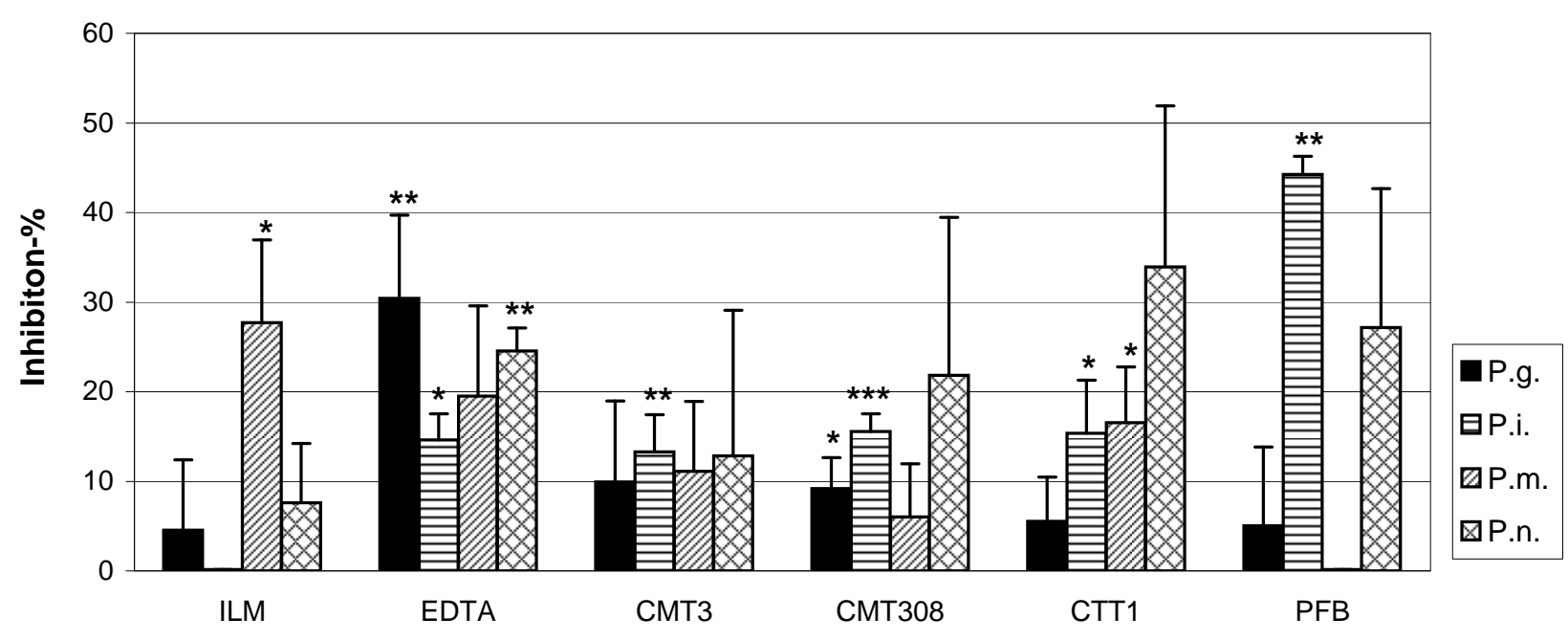

B. Inhibition of supernatants of culture media

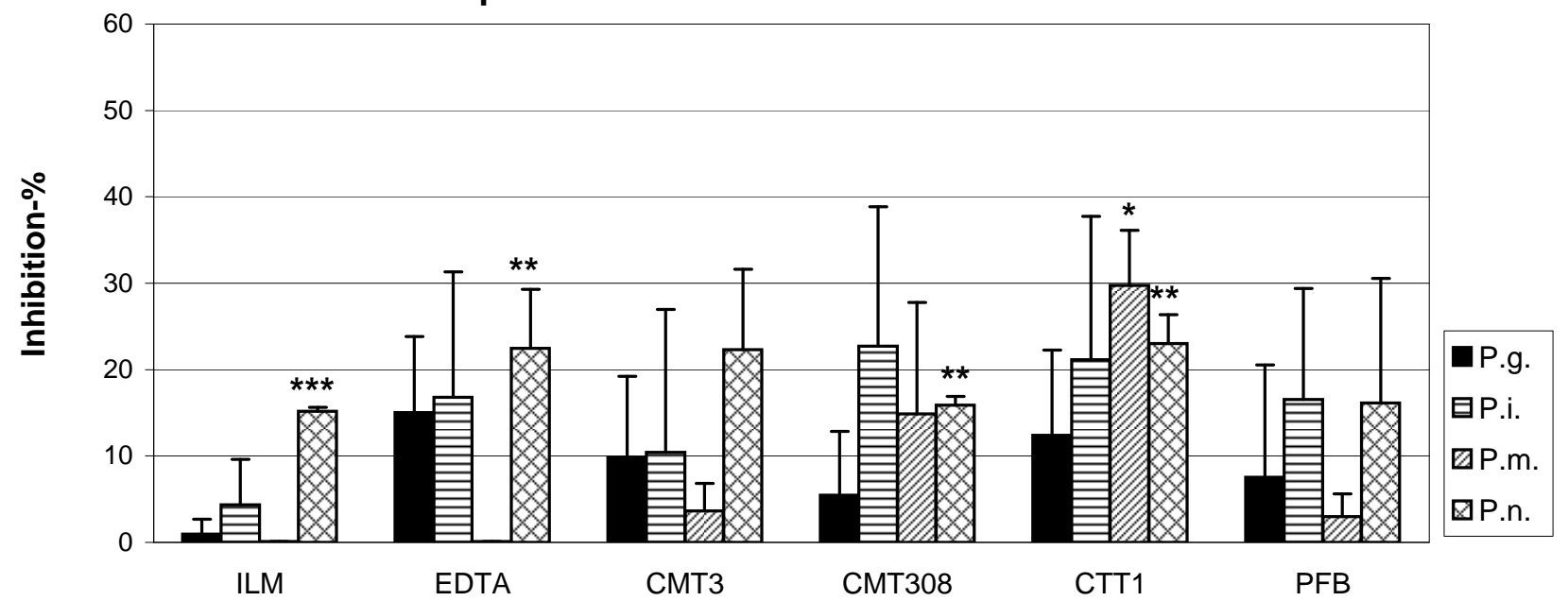

Fig. (3). The ability of proteinase inhibitors to inhibit the bacteria-based gelatinolytic activity was studied by zymography. The test was repeated 3 times and the inhibition results were compared to the control data using Student's $t$ test. $* \mathrm{P}<0.05, * * \mathrm{P}<0.01$, *** $\mathrm{P}<0.001$.

$<0.05)$. Moreover, ILM affected $P$. nigrescens supernatant proteases, EDTA affected $P$. nigrescens cell bound proteases, CMT308 $P$. intermedia cell bound proteases and $P$. nigrescens supernatant proteases, CTT1 affected $P$. nigrescens supernatant proteases, and PFB affected $P$. intermedia cell bound proteases even more significantly by reducing the enzyme activities $(P<0.01)$. In general, it seemed that all these tested synthetic inhibitors affected more effectively the bacterial cell bound proteases than the tested supernatant proteasesas shown in Fig. (3A and B).

Because A. actinomycetemcomitans and F. nucleatum showed weak gelatinolytic activities in their supernatant samples and partly in the A. actinomycetemcomitans cell fractions, the effects of synthetic inhibitors were not tested for A. actinomycetemcomitans and F. nucleatum.

\section{DISCUSSION}

The present results showed a highly complex pattern of proteinase activities of the different bacterial strains investigated which may, at least in part, indicate differences in their virulence. This was particularly clearly seen with $P$. gingivalis which is known to exert also systemic effects [26]. Our data on A. actinomycetemcomitans are totally new but this strain did not show strong proteolytic activity, however.

Inflammatory and immune reactions against periodontal pathogens are thought to trigger periodontal tissue destruction partly mediated by microbial proteolytic enzymes together with the host-derived MMPs [2, 20, 21]. The microbial proteinases also provide nutrients to the bacteria, in the form of small peptides and amino acids by degrading immunoglobulins, clotting factors, proteinase inhibitors and components of host connective tissue [21].

We observed that $P$. gingivalis, $P$. intermedia, $P$. micros and $P$. nigrescens not only produced proteolytic enzymes on the surface of their membranes, but also release proteinases into their surroundings. P. gingivalis yielded multiple molecular weight bands indicating strong proteolytic capacity in accordance with previous studies [21-22]. The major virulence factors of $P$. gingivalis include two types of trypsinlike proteinases named as ginginpains or gingivains, three 
types of collagenases, serine proteinase dipeptidyl peptidase and several kinds of hydrolytic proteinases [23-27]. The reported optimum $\mathrm{pH}$ is from 6.0-8.5, with an estimated molecular weight range from $18-300 \mathrm{kDa}$ [24, 28-29]. At least three distinct collagenolytic proteinases are produced by $P$. gingivalis [30-32]. P. gingivalis has also shown serine dipeptidyl peptidase activity with $\mathrm{pH}$ optimum of 7.5-8.5. Collectively, at the periodontal lesion site, the non-restrained action of $P$. gingivalis proteinases eventually may dysregulate most mechanisms controlling inflammatory reaction of the host.

F. nucleatum and the five serotype strains of A. actinomycetemcomitans were also found to release proteolytic enzymes but with clearly less activity. Except for the sonicated cell fraction of A. actinomycetemcomitans, serotypes b, c, and e gave the same bands as observed in their supernatant samples. Their activities could be significantly inhibited when the $\mathrm{pH}$ dropped down to 4.5. However, none of the other cell preparates of $F$. nucleatum and A. actinomycetemcomitans showed any gelatinolytic activity. Our results about A. actinomycetemcomitans partly agree with and further extend those of Uitto et al. [33] revealing a generally low cellassociated proteinase activity, and with the results of Wang [34] by showing proteolytic activity in the supernatant samples but in different $\mathrm{pH}$ values and molecular weights. Furthermore, this bacterium can degrade native type I collagen and synthetic substrate for bacterial collagenases, and the activity was found both in the bacterial cellular material and in culture medium [35]. A. actinomycetemcomitans has shown a novel alanine- and lysine-specific peptidase activity [25-26]. It does not produce trypsin-, chymotrypsin-, elastase-, dipeptidylpeptidase- or amimopeptidase-like activities [21].

Bachrach et al. [36] reported that F. nucleatum. produced a $65 \mathrm{kDa}$ proteinase which could break down extracellular matrix proteins, such as fibrinogen and fibronectin as well as type I and IV collagens. F. nucleatum and P. micros have been shown to lack trypsin-, chymotrypsin-, elastase-, dipeptidyl peptidase-, or aminopeptidase-like activity [21].

$P$. intermedia and P.nigrescens exhibit inhibitor-resistant dipeptidyl peptidase activity and arginine cysteine proteinase activity, which are biochemically very similar to those of $P$. gingivalis but with much weaker activities [21].

MMPs produced by inflammatory cells and tissue cells play an important role in the degradation and remodeling of extracellular matrix. In the pathogenesis of periodontal disease, tissue destruction caused by MMPs appears to be one of the pathogenic mechanisms [1-2, 37]. MMPs have been found to be processed in periodontitis-affected gingival tissues, oral fluids and even in dental plaque [5-9, 37]. Most likely MMP processing and activation in vivo involves cooperative action of tissue, plasma and microbial proteinases together with oxidative stress [37-38]. Okamoto et al. [38] investigated the modulation potential of various bacterial proteinases against proMMPs purified from human neutrophils (proMMP-8 and -9) and from human fibrosarcoma cells (proMMP-1). Among the six different bacterial proteinases, thermolysin family enzymes (family M4) such as Pseudomonas aeruginosa elastase, Vibrio cholerae proteinase, and thermolysin could efficiently activate all three proMMPs. The results indicate that certain bacterial proteinases can play an important role in the regulation of the tissue destruction at the site of infections [39]. Min et al. [40] described a novel biological activity of LPS preparations in promotion of extracellular matrix proteolysis by the degradation of proteinase inhibitor and the conversion of proMMP-9 by serine proteinases trypsin and plasmin.

Seguier et al. [41] suggested that MMP-9 could be a marker for the clinical severity of periodontal disease. It has been suggested that proteinases expressed by the infecting periodontal pathogens might activate latent host proMMPs to initiate or accelerate degradation of the collagenous periodontal ligament [42]. Earlier studies on the activation effect of some periodontal pathogens to proMMPs mainly focused on proMMP-8 and only few investigations studied the conversion of proMMP-9 as we did in the present investigation.

Periodontal pathogens such as $P$. gingivalis, A. actinomycetemcomitans and also Chlamydia pneumoniae in concert with inflammatory cytokines have been reported to induce processing of the host MMPs and lead to their overexpression [43]. A proteinase from P. gingivalis was shown to modulate MMP-1, MMP-3 and MMP-8 and also induce secretion of collagenase from gingival fibroblast [44]. A. actinomycetemcomitans has only been reported to trigger MMP-8 release and processing by human neutrophils [45], and stimulate human macrophage-like cells to secrete more MMPs in vitro [46].

In the present study, all the species of $P$. gingivalis, $P$. intermedia, $P$. micros, $P$. nigrescens, $F$. nucleatum and all the five serotypes of A. actinomycetemcomitans could process and fragment the $92 \mathrm{kDa}$ recombinant proMMP-9 to its lower molecular size species, some of which corresponded to the active forms with molecular weights around $60-82 \mathrm{kDa}$ $[18,40]$. The results on $P$. gingivalis activation of proMMP-9 are also in accordance with results of previous studies and $F$. nucleatum showed results similar to what Grenier and Grignon have reported [46]. However, the present results on $P$. intermedia, P. micros, $P$. nigrescens and A. actinomycetemcomitans strains are new and have not been reported earlier.

The possibility of synthetic proteinase inhibitors to limit or retard the bacteria-induced tissue destruction was also addressed in the present investigation. We studied the various synthetic MMPIs (ILM, EDTA, CMT3, CMT308, CTT1) and a serine proteinase inhibitor Pefabloc for their possible inhibition of proteolytic activity of the periodontal bacteria $P$. gingivalis, $P$. intermedia, $P$. micros, $P$. nigrescens. The results showed slight but, however, significant inhibitory effect of ILM on P. micros cell bound proteases, EDTA on $P$. gingivalis and $P$. intermedia cell bound proteases and on $P$. nigrescens supernatant proteases, CMT3 on $P$. intermedia cell bound proteases, CMT308 on P. gingivalis cell bound proteases, CTT1 on P. micros supernatant proteases and on P. intermedia and P. micros cell bound proteases. Furthermore, a suppressive function of their gelatinolytic activity was observed with ILM on $P$. nigrescens supernatant proteases, EDTA on P. nigrescens cell bound proteases, CMT308 on P. intermedia cell bound proteases and on $P$. nigrescens supernatant proteases, and CTT1 on $P$. nigrescens supernatant proteases. Synthetic MMP-inhibitors, either selective (CTT-1) or non-selective (ILO, EDTA, CMTs), reduce the bacterial proteinase activities in a nonspecific manner and with the same efficiency [1, 19, 37]. 
Pefabloc showed a more pronounced effect on $P$. intermedia cell bound proteases. In general, it seemed that all these synthetic proteinase inhibitors demonstrated more efficient inhibition of cell fraction bound microbial proteinases than on proteinases released into the culture medium. Overall, our findings together with Grenier et al. [47] suggest that certain synthetic anti-proteolytics eventually together with some anti-microbial agents can affect the survival and proteolytic agents of periodontopathogenic bacteria.

In conclusion, the present results showed that the several periodontal bacteria investigated, i.e., $P$. gingivalis, $P$. intermedia, $P$. micros, $P$. nigrescens, $F$. nucleatum and A. actinomycetemcomitans, can produce cell bound and extracellular gelatinolytic proteinases which, in turn, may activate latent proMMP-9. This may suggests a co-operative cascade in the pathogenesis of oral tissue destruction. Synthetic proteinase inhibitors such as MMPIs and Pefabloc exhibit slight inhibitory effects on the proteolytic activities of these bacteria without inhibiting them completely, however. In future such synthetic inhibitors may prove to be useful tools in treatment of oral tissue destruction.

\section{ACKNOWLEDGEMENTS}

This study was co-funded by the Chinese Scholarship Council (CSC) of the Education Ministry of China and the Institute of Dentistry, University of Helsinki, Finland. The author TS was funded by the Academy of Finland, and by grants TYH 5306, TYH 6104, TYH 7114 and T1020Y0002 by the Helsinki University Central Hospital (HUCH). The author JHM was funded by Päivikki and Sakari Sohlberg Foundation, Helsinki, Finland, and by grant TYH 3245 by the HUCH. The authors greatly appreciate the technical assistance of Ritva Keva and Jukka Inkeri as well as shared discussions with DDS Pirjo Pärnänen.

\section{REFERENCES}

[1] Sorsa T, Tjäderhane L, Salo T. Matrix metalloproteinases (MMPs) in oral diseases. Oral Dis 2004; 10: 311-318.

[2] Uitto VJ, Overall CM, McCulloch C. Proteolytic host cell enzymes in gingival crevice fluid. Periodontol 2000 2003; 31: 77-104.

[3] Weiss SJ. Tissue destruction by neutrophils. N Engl J Med 1990; 320: 365-376

[4] Mancini S, Romanelli R, Laschinger CA, Overall CM, Sodek J, McCulloch CA. Assessment of a novel screening test for neutrophil collagenase activity in the diagnosis of periodontal diseases. J Periodontol 1999; 70: 1292-1302.

[5] Romanelli R, Mancini S, Laschinger C, Overall CM, Sodek J, McCulloch CA. Activation of neutrophil collagenase in periodontitis. Infect Immun 1999; 67: 2319-2326.

[6] Lee W, Aitken S, Sodek J, McCulloch CA. Evidence of a direct relationship between neutrophil collagenase activity and periodontal tissue destruction in vivo: role of active enzyme in human periodontitis. J Periodontal Res 1995; 30: 23-33.

[7] Mäntylä P, Stenman M, Kinane DF, Tikanoja S, Luoto H, Salo T, Sorsa T. Gingival crevicular fluid collagenase-2 (MMP-8) test stick for chair-side monitoring of periodontitis. J Periodont Res 2003; 38: 436-439.

[8] Owen CA, Hu Z, Lopez-Otin C, Shapiro SD. Membrane-bound matrix metalloproteinase- 8 on activated polymorphonuclear cells is a potent tissue inhibitor of metalloproteinase-resistant collagenase and serpinase. J Immunol 2004; 172: 7791-7803.

[9] Sorsa T, Ding YL, Ingman T, Salo T, Westerlund U, Haapasalo M, Tschesche H, Konttinen Y. Cellular source, activation and inhibition of dental plaque collagenase. J Clin Periodontol 1995; 22: 70917.

[10] Söder B, Jin LJ, Wickholm S. Granulocyte elastase, matrix metalloproteinase-8 and prostaglandin E2 in gingival crevicular fluid in matched clinical sites in smokers and non-smokers with persistent periodontitis. J Clin Periodontol 2002; 29: 384-91.

[11] Tayebjee MH, Tan KT, MacFadyen RJ, Lip GY. Abnormal circulating levels of metalloproteinase 9 and its tissue inhibitor 1 in angiographically proven peripheral arterial disease: relationship to disease severity. J Intern Med 2005; 257: 110-6.

[12] Kalela A, Ponnio M, Koivu TA, Höyhtyä M, Huhtala H, Sillanaukee P, Nikkari ST. Association of serum sialic acid and MMP-9 with lipids and inflammatory markers. Eur J Clin Invest 2000; 30: 99-104.

[13] Söder B, Airila Månsson S, Kari K, Meurman JH. Levels of matrix metalloproteinases -8 and -9 with simultaneous presence of periodontal pathogens in gingival crevicular fluid as well as matrix metalloproteinase-9 and cholesterol in blood. J Periodont Res 2006; 41 : 411-417.

[14] Kubota T, Nomura T, Takahashi T, Hara K. Expression of mRNA for matrix metalloproteinases and tissue inhibitors of metalloproteinases in periodontitis-affected human gingival tissue. Arch Oral Biol 1996; 41: 253-262.

[15] Paster BJ, Boches SK, Galvin JL, Ericson RE, Lau CN, Levanos VA, Sahasrabudhe A, Dewhirst FE. Bacterial diversity in human subgingival plaque. J Bacteriol 2001; 183: 3770-83.

[16] Listgarten MA, Loomer PM. Microbial identification in the management of periodontal diseases. A systematic review. Ann Periodontol 2003; 8: 182-92.

[17] Golub LM, Lee HM, Ryan ME, Giannobile WV, Payne J, Sorsa T. Tetracyclines inhibit connective tissue breakdown by multiple nonantimicrobial mechanisms. Adv Dent Res 1998; 12: 12-26

[18] Sorsa T, Salo T, Koivunen E, Tyynela J, Konttinen Y T, Bergmann U, Tuuttila U, Niemi E, Teronen O, Heikkilä P, Tschesche H, Leinonen J, Osman S, Stenman UH. Activation of type IV procollagenases by human tumor-associated trypsin-2. J Biol Chem 1997; 272: 21067-21074

[19] Koivunen E, Arap W, Valtanen H, Rainisalo A, Penate Medina O, Heikkilä P, Kantor C, Gramberg CG, Salo T, Konttinen YTK, Sorsa T, Ruoslahti E, Pasqualini R. Tumor targeting with a selective gelatinase inhibitor. Nat Biotech 1999; 17: 768-774.

[20] Garlet GP, Cardoso CR, Silva TA, Ferreira BR, Ávila-Campos MJ, Cunha FQ, Silva JS. Cytokine pattern determines the progression of experimental periodontal disease induced by Actinobacillus actinomycetemcomitans through the modulation of MMPs, RANKL, and their physiological inhibitors. Oral Microbiol Immunol 2006; 21: 12-20.

[21] Eley BM, Cox SW. Proteolytic and hydrolytic enzymes from putative periodontal pathogens: characterization, molecular genetics, effects on host defences and tissues and detection in gingival crevice fluid. Periodontol 2000 2003; 31: 105-124.

[22] Potempa J, Banbula A, Travis J. Role of bacterial proteinases in matrix destruction and modulation of host responses. Periodontol 2000 2000; 24: 153-92.

[23] De Carlo AA, Windsor LJ, Boden MK, Harber GJ, BirkedalHansen B, Birkedal-Hansen H. Activity and novel processing of matrix metalloproteinases by a thiolproteinase from the oral anaerobe Porphyromonas gingivalis. J Dent Res 1997; 76: 1260-1270.

[24] Fujimura S, Nakamura T. Multiple forms of proteinases of Bacteroides gingivalis and their cellular location. Oral Microbiol Immunol 1989; 4: 227-229.

[25] Gazi MI, Cox SW, Clark DT, Eley BM. A comparison of cysteine and serine proteinases in human gingival crevicular fluid with host tissue, saliva and bacterial enzymes by analytical isoelectric focusing. Arch Oral Biol 1996; 41: 393-400.

[26] Gazi MI, Cox SW, Clark DT, Eley BM. Characterisation of proteinase activities in Capnocytophage spp., Porphyromonas gingivalis, Prevotella spp., Treponema denticola and Actinobacillus cetemcomitans. Oral Microbiol Immunol 1997; 12: 240-248.

[27] Travis J, Pike R, Imamura T, Potempa J. Porphyromonas gingivalis proteinases as virulence factors in the development of chronic periodontistis. J Periodontal Res 1997; 32: 120-125.

[28] Lantz MS, Allen RD, Chiorowski PK, Holt CS. Purification and immunolocalisation of a cysteine proteinase from Porphyromonas gingivalis. J Periodontal Res 1993; 28: 467-469.

[29] Chen Z, Potempa J, Polanowski A, Wikström M, Travis J. Purification and characterization of a $50-\mathrm{kDa}$ cysteine proteinase (gingipain) from Porphyromonas gingivalis. J Biol Chem 1992; 267: 18896-18901. 
[30] Kato T, Takahashi N, Kuramitsu H. Sequence analysis and characterization of the Porphyromonas gingivalis ptrC gene, which expresses a novel collagenase activity. J Bacteriol 1992; 174: 38893895 .

[31] Lawson DA, Meyer TE. Biochemical characterization of Porphyromonas (Bacteroides) gingivalis collagenase. Infect Immun 1992; 60: 1524-1529.

[32] Sojar HT, Lee J-Y, Bedi GS, Genco RJ. Purification and characterization of a proteinase from Porphyromonas gingivalis capable of degrading salt-solubilized collagen. Infect Immun 1993; 61: 2369-2376.

[33] Uitto VJ, Haapasalo M, Laakso T, Salo T. Degradation of basement membrane collagen by proteinases from some anaerobic oral microorganisms. Oral Microbiol Immun 1988; 3: 97-102.

[34] Wang P-L, Shirasu S, Shinohara M, Daito M, Fujii T, Kowashi Y, Ohura K. Purification and characterization of a trypsin-like proteinase form the culture supernatant of Actinobacillus actinomycetemcomitans Y4. Eur J Oral Sci 1999; 107: 147-153.

[35] Rozanis J, Van Wart HE, Bond MB, Slots J. Further studies on collagenase of Actinobacillus actinomycetemcomitans. J Dent Res 1983; 62: 300

[36] Bachrach G, Rosen M, Bellalou M, Naor R, Sela MN. Identification of a Fusobacterium nucleatum $65 \mathrm{kDa}$ serine proteinase. Oral Microbiol Immun 2004; 19: 155-159.

[37] Sorsa T, Tjäderhane L, Konttinen YT, Lauhio A, Salo T, Lee HM, Golub LB, Brown DL, Mäntylä P. Matrix metalloproteinases: contribution to pathogenesis, diagnosis and treatment of periodontal inflammation. Ann Med 2006; 38: 306-321

[38] Van den Steen PE, Dubois B, Nelissen I, Rudd PM, Dwek RA, Opdenakker G. Biochemistry and molecular biology of gelatinase B or matrix metalloproteinase-9 (MMP-9). Crit Rev Biochem Mol Biol 2002; 37: 375-536.

[39] Okamoto T, Akaike T, Suga M, Tanase S, Horie H, Miyajima S, Ando M, Ichinose Y, Maeda H. Activation of human matrix metal- loproteinases by various bacterial proteinases. J Biol Chem 1997; 272: 6059-6066.

[40] Min D, Moore AG, Bain MA, Breit SN, Lyons JG. Activation of macrophage promatrix metalloproteinase- 9 by lipopolysaccharideassociated proteinases. J Immunol 2002; 168: 2449-2455.

[41] Seguier S, Gogly B, Bodineau A, Godeau G, Brousse N. Is collagen breakdown during periodontistis linked to inflammatory cells and expression of matrix metalloproteinases and tissue inhibitors of metalloproteinases in human gingival tissue? J Periodontol 2001; 72: 1398-1406.

[42] Neumann U, Kubota H, Frei K, Ganu V, Leppert D. Charaterization of Mca-Lys-Pro-Leu-Gly-Leu-Dpa-Ala-Arg.NH2, a fluorogenic substrate with increased specificity constants for collagenases and tumor necrosis factor converting enzyme. Annal Biochem 2004; 328: 166-173.

[43] Pozo P, Valenzuela M A, Melej C, Zaldivar M, Puente J, Martinez B, Gamonal J. Longitudinal analysis of metalloproteinases, tissue inhibitors of metalloproteinases and clinical parameters in gingival crevicular fluid from periodontitis-affected patients. J Peridont Res 2005; 40: 199-207.

[44] Imamura T, Matsushita K, Travi J, Potempa J. Inhibition of trypsinlike cysteine proteinases (4 gingipains) from Porphyromonas gingivalis by tetracycline and its analogues. Antimicrob Agents Chemother 2001; 45: 2871-2876.

[45] Claesson R, Johansson A, Belibasakis G, Hanström L3, Kalfas S. Release and activation of matrix metalloproteinase- 8 from human neutrophils triggered by the leukotoxin of Actinobacillus actinomycetemcomitans. J Periodont Res 2002; 37: 353-359.

[46] Grenier D, Grignon L. Response of human macrophage-like cells to stimulation by Fusobacterium nucleatum ssp. nucleatum lipopolysaccharide. Oral Microbiol Immunol 2006; 21: 190-196.

[47] Grenier D, Roy E, Mayrand D. Modulation of Porphyromonas gingivalis proteinase activity by suboptimal doses of antimicrobial agents. J Periodontol 2003; 73: 1316-1319

(C) Bao et al.; Licensee Bentham Open.

This is an open access article distributed under the terms of the Creative Commons Attribution License (http://creativecommons.org/licenses/by/2.5/), which permits unrestrictive use, distribution, and reproduction in any medium, provided the original work is properly cited. 